Technological University Dublin

DÜBLIN

ARROW@TU Dublin

2008-07-01

\title{
Assessing the Effect of Product Variability on the Management of the Quality of Mushrooms (Agaricus bisporus)
}

\author{
Catherine Barry-Ryan \\ Technological University Dublin, Catherine.Barryryan@tudublin.ie \\ Jesus Maria Frias \\ Technological University Dublin, Jesus.Frias@tudublin.ie \\ Leixuri Aguirre \\ Technological University Dublin, leixuri.aguirre@tudublin.ie
}

See next page for additional authors

Follow this and additional works at: https://arrow.tudublin.ie/schfsehart

Part of the Food Science Commons, and the Plant Sciences Commons

\section{Recommended Citation}

Barry-Ryan, C., Frias,J., Aguirre, L.,Grogan,H.: Assessing the effect of product variability on the management of the quality of mushrooms (Agaricus bisporus).Postharvest Biology and Technology 49 (2008),pp. 247-254. doi:10.1016/j.postharvbio.2008.01.014

This Article is brought to you for free and open access by the School of Food Science and Environmental Health at ARROW@TU Dublin. It has been accepted for inclusion in Articles by an authorized administrator of ARROW@TU Dublin. For more information, please contact arrow.admin@tudublin.ie, aisling.coyne@tudublin.ie, gerard.connolly@tudublin.ie.

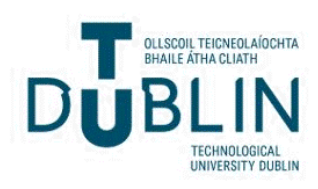


Authors

Catherine Barry-Ryan, Jesus Maria Frias, Leixuri Aguirre, and Helen Grogan

This article is available at ARROW@TU Dublin: https://arrow.tudublin.ie/schfsehart/101 
Dublin Institute of Technology

ARROW@DIT

2008-07-01

\section{Assessing the effect of product variability on the management of the quality of mushrooms (Agaricus bisporus)}

Catherine Barry-Ryan

Jesus Frias

Leixuri Aguirre

Helen Grogan

Follow this and additional works at: http://arrow.dit.ie/schfsehart

Part of the Food Science Commons, and the Plant Sciences Commons

This Article is brought to you for free and open access by the School of

Food Science and Environmental Health at ARROW@DIT. It has been

accepted for inclusion in Articles by an authorized administrator of

ARROW@DIT. For more information, please contact

yvonne.desmond@dit.ie, arrow.admin@dit.ie. 


\title{
Assessing the effect of product variability on the management of the quality of mushrooms (Agaricus bisporus)
}

\author{
Postharvest Biology and Technology 49 (2008) 247-254 \\ Leixuri Aguirre a, Jesus M. Frias a,*, Catherine Barry-Ryan a, Helen Grogan b \\ a. School of Food Science and Environmental Health, Dublin Institute of Technology, Cathal Brugha St, Dublin 1, \\ Ireland \\ b. Teagasc, Kinsealy R\&D Centre, Malahide Road, Dublin 17, Ireland
}

\begin{abstract}
To study the shelf-life of mushrooms, over 25 batches were subjected to three storage temperatures $(\mathrm{T})(5,15$ and 25 .C) and three storage relative humidity (RH) levels (70, 80 and $90 \%$ ). The effect of $\mathrm{T}$ and the $\mathrm{RH}$ on the kinetics of quality attributes of the batches was studied by measuring water activity, turgor, colour (L, $a^{*}$ and $b^{*}$ in the Hunter Scale) and weight loss of three different tissues (cap, gills and stipe) of the mushroom. Linear mixed effect models, comprising polynomial models to describe quality kinetics and allowing for batch-to-batch and inside-batch nested variability structure, were built. The resulting models described changes in the six quality factors with time, their kinetic dependence on temperature and relative humidity and estimated the variability components in a typical retailer situation. Significant quadratic effects, pointing to optimal storage conditions were found for the temperature ( $\mathrm{L}$ and a values, $\mathrm{b}$ value, water activity, turgor and weight) and for the relative humidity ( $\mathrm{L}$ and a values, $\mathrm{b}$ value, water activity and total weight). Optimal storage conditions point to a practice of low temperature and high relative humidity to preserve product weight, although other properties can be optimally preserved using higher storage temperatures and therefore pointing to possible cost savings in storage. Significant batch-to-batch and inside-batch variability components were identified, giving an estimate of the variability expected on the management of different quality attributes of such a biological product in an agricultural retail scenario.
\end{abstract}

Keywords: Modelling; Shelf-life; Mushrooms

\section{Introduction}

Mushrooms have a short postharvest shelf-life of 3-4 days compared to other supermarket produce (i.e., fresh vegetables), mainly because they have no cuticle to protect them from physical damage or microbial attack and water loss (Burton and Noble, 1993). Their high respiration rate (Varoquaux et al., 1999; CliffeByrnes and O'Beirne, 2007) and high water content (Mahajan et al., 2007a) make them prone to microbial spoilage and to exhibit enzymatic browning (Brennan et al., 1999, 2000).

Maturity, transpiration, respiration and pathogenic fungi and bacteria (Pai, 2000) as well as storage conditions such as temperature, relative humidity and gas composition of the storage atmosphere affect quality losses (Burton and Noble, 1993; Roy et al., 1995; Mahajan et al., 2007b).
Quality in mushrooms can be assessed as a composite of visual appearance, freshness, colour, size, maturity stage, development stage, firmness, turgor, microbial growth, clearness, blemish-free, weight loss and blotching (Burton, 1989; Carey and O'Connor, 1991; Vizhanyo and Felfoldi, 2000; Pardo et al., 2001). From the consumer point of view the quality indices of mushrooms in order of importance are: freshness, whiteness, clearness, uniformity and closedness (Burton, 1986).

A good quality freshly picked mushroom would have a reflectance (L-value) of 85.5-90. A poor quality of mushroom would have a value below 79.5 (Burton et al., 1987). The cap growth results in gradual opening of the mushroom cap (Lukkasse and Polderdijk, 2003).

Moisture losses are the principal causes of weight loss in the mushroom, which may result in agricultural product losses. Edible mushrooms tend to be high in moisture and especially Agaricus bisporus (Beelman et al., 2003). The dry matter (percent solids) content of $A$. bisporus is $7.84 \%$ (with a standard error of 0.70) (Burton and Noble, 1993), with small or no differences between flushes and crops (Frankhuizen and Boekestein, 
1995). During postharvest storage, the cells are damaged and generally there is a water transfer out from the cells. This water loss increases the turgor and the hardness of the mushrooms (Beecher et al., 2000).

Despite the efforts of agricultural production, classification and packaging, one of the main problems in mushroom technology (as in many fresh products) is the uncontrollable effect that product variability has on the management of the product. From a retailer's point of view different batches of mushrooms may arrive at a different maturity stage and inside every batch there is natural product heterogeneity. This results in important storage losses from the retailer-producer point of view (Talasila and Cameron, 1995; Fonseca et al., 2002; Hertog et al., 2004, 2007a,b).

Mixed effect models present a statistical framework that allows for a simultaneous characterisation of the main effects that are going to influence an experiment, together with the estimation of the different components that affect the variability intrinsic to the problem being observed (Pinheiro and Bates, 2000). While in the agricultural and the pharmaceutical research area variability components have been taken into account in the stages of experimental design and model estimation, via the development of split-plot experiments and dose-response curves (Davidian and Giltinan, 1995), the food research area traditionally has not employed statistical tools appropriate for high variability. Only recently have mixed effect models received more attention to estimate the different components of variability in sensory analysis (Gabrielen, 2001), in microbial growth predictive models (Shorten et al., 2004), in postharvest technology (Lammertyn et al., 2003, 2004; Schouten et al., 2004; Tijskens et al., 2007) and in food packaging design (Fonseca et al., 2002). Given that an estimation of variability can provide information to perform uncertainty assessment and risk analysis that can help to manage the produce quality, these models can provide information for food related problems where variability is important and other statistical methodologies are not as suitable (Hertog et al., 2007b).

The aim of this work is: (1) to analyze the effect that temperature and relative humidity have on the quality and shelf-life of mushrooms, in a situation with high product variability, and to determine the best conditions to store mushrooms, (2) to estimate the different components of variability that affect the shelf-life using linear mixed effect models, and (3) to assess the effect that variability will have on the shelf-life.

\section{Materials and methods}

\subsection{Experimental design}

Closed cup mushrooms (A. bisporus) white, close, uniform, clear, and fresh and with an apparent density of $0.547 \mathrm{~g} / \mathrm{cm} 3$ were purchased from a local supermarket on produce arrival day (1 day after harvest). Mushroom spawn producers generally employ different cultivars (2-3) during the season. Those cultivars have with very similar quality characteristics and are alternated to prevent losses due to pest and viruses. The study aimed to represent a typical situation of a medium size retailer
Table 1

Experimental design

\begin{tabular}{lll}
\hline Temperature $(\circ \mathrm{C})$ & Relative humidity $(\%)$ & No. of batches \\
\hline 5 & 70 & 4 \\
5 & 80 & 4 \\
5 & 90 & 4 \\
15 & 70 & 2 \\
15 & 80 & 2 \\
15 & 90 & 2 \\
25 & 70 & 3 \\
25 & 80 & 2 \\
25 & 90 & 2
\end{tabular}

receiving a product over 1.5 years with a reasonable variation of spam origin, producer, cultivar and flush.

Accelerated experiments, in order to study senescence, water transfer, colour and texture kinetics were performed in an environmental incubator (MLR-350 HT, SANYO Electric Biomedical Co. Ltd., Japan). Three temperatures (T) levels (5, 15 and $25 \circ \mathrm{C})$ and three relative humidity $(\mathrm{RH})$ levels $(70,80$ and 90) in a full factorial design were selected, based on previous studies (Pai, 2000; Escriche et al., 2001).

Mushroom shelf-life is commonly taken as 3-4 days. In order to better understand the progression of senescence and decay phenomena involved in the shelf-life of mushrooms, the study involved the sampling of mushrooms at each of the environmental conditions up to 10 days.

The experiments were repeated (Table 1) and quality parameters analyzed were mass transfer, colour, appearance and turgor in each of the different tissues of the mushroom (cap, gills and stipe). The total number of batches was 25 , including 2461 samples, which accounted for four analytical measurements in each of the three tissue parts of the mushroom.

\subsection{Water activity}

The water activity of the mushroom tissues (cap, gills and stipe) was measured using a chilled mirror water activity measurement instrument (AQUALAB Series 3TE, Decagon Devices Inc., WA, USA). The water activity of stipe, gills and cap of the mushrooms during storage was measured.

\subsection{Colour}

Mushroom tissues colour was measured using a Hunter colorimeter in the $L, a^{*}, b^{*}$ scale (Colour Quest XE Hunter Lab, VA, USA). The colour measurement was performed three times and an average taken.

\subsection{Cell turgor potential}

Turgor pressure is generally thought to be partly responsible for hyphal growth and for maintaining the volume, form and rigidity of mushroom cells in sporophores by internal pressure on cell walls (Money, 1994). The water potential ( $\left.\psi_{\mathrm{w}}\right)$ of fresh mushrooms is a measure of the freely available water for microbial growth. It is the sum of the osmotic, turgor and matric 
potentials (Beecher et al., 2000):

$\Psi_{\mathrm{wf}}=\Psi_{\mathrm{s}}+\Psi_{\mathrm{p}}+\Psi_{\mathrm{m}}$

where $\psi_{\mathrm{w}}$ is the water potential, $\psi_{\mathrm{s}}$ the solute (osmotic) potential, $\Psi_{\mathrm{p}}$ the turgor potential and $\Psi_{\mathrm{m}}$ the matric potential (Griffin, 1981; Eamus and Jennings, 1984).

The water potential of a mushroom whose cellular tissue has been completely destroyed is:

$\psi_{\mathrm{wt}}=\psi_{\mathrm{s}}+\psi_{\mathrm{m}}$

The turgor potential of mushroom tissues was measured by determining the total water potential of a fresh mushroom ( $\psi \mathrm{wf})$, then subjecting the same mushroom to a freeze-thaw procedure (Beecher et al., 2000) to destroy the cellular membranes and then measuring again the total water potential $(\psi \mathrm{wt})$. The difference between those two water potentials was the turgor potential.

\subsection{Moisture content}

Moisture content was determined following the AOAC methods (Refs. 32.1.02 and 32.1.03, AOAC 16th Edition (1995).

\subsection{Mathematical models}

A linear mixed effect model can be described as (Gurka, 2006):

$$
\begin{aligned}
& y \sim X \beta+Z b+\varepsilon, \quad b \sim N\left(0, \sigma_{2} \Sigma\right), \quad \varepsilon \sim N\left(0, \sigma_{2} l\right), \\
& \varepsilon \perp b
\end{aligned}
$$

where $y$ is the dependent variable vector, $X$ is the matrix of independent variables, $\beta$ is the vector of fixed effect parameters that characterise the effect of the independent variables on the response, $\mathrm{Z}$ is the model matrix that characterises the random effect structure and $b$ is the random effect vector associated. Finally $\varepsilon$ is the additive error term of the model. The random effects and the error term are assumed to follow a normal distribution with $\Sigma$ being the precision matrix of the random effect relatively to the noise term $\varepsilon$ and the symbol $\perp$ represents the independence between random variables.

The model proposed to describe the dependence of the different quality parameter kinetics on temperature and relative humidity had the following components:

1. The kinetics with time of the quality factors were inspected graphically and a linear dependence with time was seen for $\mathrm{a}, \mathrm{b}$ and turgor. The logarithmic transform $\ln (\mathrm{L}), \ln (\mathrm{aw})$ and $\ln$ (weight) was employed to linearise the kinetics.

2. A fixed effect part in the form of three different origins and slopes with time for each of the mushroom tissues (cap, gills and stipe).

3. Considering that the $\mathrm{RH}$ is just a relative measurement of the water gradient, which depends on itself on both the storage relative humidity and the temperature, the slope with time of the quality factor was assumed to follow a polynomial dependence of the form:
4. A two nested random effect structure, taking into account batches of mushrooms and individuals inside a batch, following a normal distribution, was considered for each individual tissue.

This model (the "saturated model") had 18 fixed coefficients and six random effects to estimate and a model simplification procedure was followed to reduce it.

\subsection{Model building}

The model building process followed a series of steps:

1. The saturated model was built with all the fixed and random effect terms.

2. A summary of the model was produced with t-statistics for each individual model coefficient and Wald-tests for each model term.

3. Based on the Wald-test statistics of significance for the fixed effect non-significant terms of the polynomial model were eliminated.

4. A summary of the new model was produced with Wald-tests for each model term.

5. The logarithm likelihood ratio test and the Akaike Information Criteria were employed to compare the new model with the previous one.

Steps 2-5 were repeated until a satisfactory model reduction was achieved. Finally, random effects or individual terms in the model that appeared to be negligible were reduced. In order to assess the suitability of the best model, the random effects and residuals were studied for seasonality effects. All statistical analysis was performed using the libraries nlme and lme4 from the R-statistical analysis package (Pinheiro and Bates, 2000).

\section{Results and discussion}

Table 2 shows the estimated model parameters affecting the six quality factors. Significant effects of temperature and relative humidity on the slope of the decay kinetics could be observed in all quality indicators (tested via Markov Chain Monte Carlo simulation). Significant interactive effects between temperature and relative humidity were observed in all quality indicators except the turgor potential. Most importantly, significant quadratic effects were found, pointing to possible conditions were the L-value, a-value, b-value water activity and weight might be optimally preserved.

Fig. 1 shows the typical kinetics of the quality attributes of a batch during the storage experiments. The average behaviour predicted by the model (corresponding to the fixed part of the model) can be seen as well. The differences between the particular behaviour of the batch and the average provide an idea of the importance of repetition and averaging in the postharvest technology. In fact, if only one particular batch of produce would be used at this experimental level, instead of repeating the experiment with four batches, the model predictions would likely be biased. 
Table 2

Estimated parameters from the linear mixed effect models

\begin{tabular}{|c|c|c|c|c|c|c|c|c|c|}
\hline \multicolumn{10}{|c|}{ Log (Aw) Fixed Effects } \\
\hline Cap & \multicolumn{9}{|c|}{$-9 e-3_{(3 e-5)}+$ Daysx $\left[-8.4 e-3_{(7 e-4)} \times T-8.2 e-4_{(\theta e-5)} \times T \times R H+1.1 e-4_{(1,8 e-5)} \times T^{2}-1.0 e-8_{(3 e-8)} \times T^{2} \times R H^{2}\right]$} \\
\hline Gills & \multicolumn{9}{|c|}{ 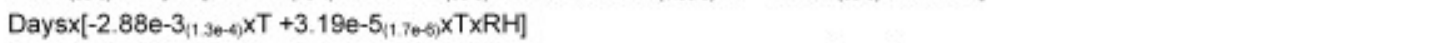 } \\
\hline Stipe & \multicolumn{9}{|c|}{$-6.3 e-3_{(8 e-4)}+$ Daysx $\left[-1.61 e-3_{(1.10-4)} \times T+1.65 e-5(1.40-0) \times T \times R H+4 e-10_{(20-10)} \times T^{2} \times R^{2} H^{2}\right]$} \\
\hline \multicolumn{10}{|c|}{ Random Effects } \\
\hline & Cap & Gills & Stipe & & Cap & Gills & Stipe & & \\
\hline$\sigma_{\text {Qstan }}$ & $1.2 \mathrm{e}-2_{(9 \mathrm{e}-2)}$ & $1.4 e-2_{(5 e-3)}$ & $1.3 \mathrm{e}-2_{(9 \mathrm{a}-3)}$ & $\sigma_{\text {Samole }}$ & $2.1 \mathrm{e}-2_{(3 \mathrm{e}-3}$ & $2.0 e-2_{(30-3)}$ & $2.0 \mathrm{e}-2_{(40-3)}$ & $\sigma_{\text {tmmor }}$ & $56-3(46-3)$ \\
\hline \multicolumn{10}{|c|}{ Turgor Fixed Effects } \\
\hline Cap & \multicolumn{9}{|c|}{$106_{(13)}$} \\
\hline Gills & \multicolumn{9}{|c|}{$1.3,5$, DaysxT } \\
\hline Stipe & \multicolumn{9}{|c|}{$94_{(16\}^{-}}$-Daysx $\left[2.1_{(0.6)} \times T+0.06_{\mid 0.03)} \times T^{2}\right]$} \\
\hline \multicolumn{10}{|c|}{ Random Effects } \\
\hline & Cap & Gills & Stipe & & Cap & Gills & Stipe & & \\
\hline$\sigma_{\text {Benth }}$ & & & & $\sigma_{\text {Sintien }}$ & $4 \cdot 1 \mathrm{e}+2\{70+1\}$ & $8.5 e+2(90+1)$ & $42 \mathrm{e}+2(9 \mathrm{e}+1)$ & $\sigma_{\text {Emer }}$ & $3.1 e+1$ (c.1e+2) \\
\hline \multicolumn{10}{|c|}{$\log (\mathbf{L})$ Fixed Effects } \\
\hline Cap & \multirow{3}{*}{\multicolumn{9}{|c|}{ 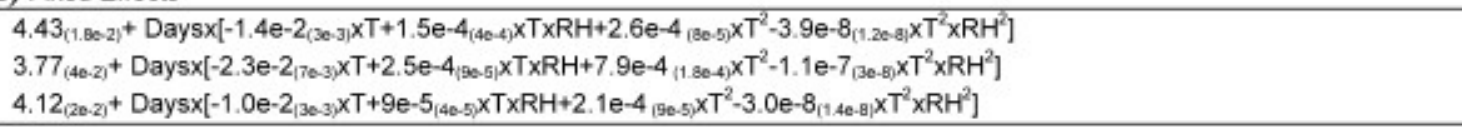 }} \\
\hline Gills & & & & & & & & & \\
\hline Stipe & & & & & & & & & \\
\hline \multicolumn{10}{|c|}{ Random Effects } \\
\hline & Cap & Gills & Stipe & & Cap & Gills & Stipe & & \\
\hline$\sigma_{\text {Batch }}$ & $8 e-2_{\left|{ }^{2}-2\right|}$ & $2.1 e-1_{(1,4 e-1)}$ & $9 e-2_{\mid[e-2]}$ & Sample & $7 e-2_{(2+2)}$ & $2.1 e-1_{(20-2)}$ & $1.1 \mathrm{e}-1_{(30-2)}$ & $\sigma_{\text {Emor }}$ & $3 e-2(a-2)$ \\
\hline \multicolumn{10}{|c|}{ a Fixed Effects } \\
\hline Cap & \multicolumn{9}{|c|}{$1.38_{(0.2)}+$ Daysx $\left[2.3 e-1_{(4 e-2)} \times T-2.4 e-3_{(5 e-4)} \times T \times R H-5.7 e-3_{(1.0 e-3)} \times T^{2}+7.4 e-7_{(1.6 e-7)} \times T^{2} \times R H^{2}\right]$} \\
\hline Gills & \multicolumn{9}{|c|}{$3.73_{(1.8 e-1)}+1.40 \mathrm{e}-4_{(1.8 e-5)}$ DaysxTxRH } \\
\hline Stipe & \multicolumn{9}{|c|}{$4.6_{(0.3)}+1.5 \mathrm{e}-3_{(1.0 \mathrm{e}-4)}{\text { Days } x T^{2}}^{2}$} \\
\hline \multicolumn{10}{|c|}{ Random Effects } \\
\hline & Cap & Gills & Stipe & & Cap & Gills & Stipe & & \\
\hline$\sigma_{\text {Batch }}$ & $0.9_{(0.6)}$ & $1.2_{(0.8)}$ & $1.5_{[1.0]}$ & Sample & & & & $\sigma_{\text {Emor }}$ & $1.0_{(0,7)}$ \\
\hline \multicolumn{10}{|c|}{ b Fixed Effects } \\
\hline Cap & \multicolumn{9}{|c|}{$1.36_{(0.0)}+$ Days $x\left[0.39_{(0.00)} \times T-3.7 e-3_{(1.10-3)} \times T \times f\right.$} \\
\hline Gills & \multicolumn{9}{|c|}{$7.2(0.4)-7 e-8_{(2 \theta-8)}$ Days $x T^{2} \mathrm{RH}^{2}$} \\
\hline Stipe & \multicolumn{9}{|c|}{$15.5(0.5)-1.17 e-3_{(1.5 e-4)}$ Daysx T $T^{2}$} \\
\hline \multicolumn{10}{|c|}{ Random Effects } \\
\hline & Cap & Gills & Stipe & & Cap & Gills & Stipe & & \\
\hline$\sigma_{\text {Bstch }}$ & $1.57_{\langle 1.1\}}$ & $2.0_{(1.5)}$ & $3(z)$ & Sample & $2.4(0.3)$ & 3.70 .5 & $3.0_{(0.5)}$ & $\sigma_{\mathrm{Emer}}$ & $0.9_{104}$ \\
\hline \multicolumn{10}{|c|}{ Log(Weight) Fixed Effects } \\
\hline \multicolumn{10}{|c|}{$\begin{array}{l}\text { Whole Mushroom } 3.13(0.05)+D \\
\text { Random Effects }\end{array}$} \\
\hline & Whole Mus & om & & & & & & & \\
\hline$\sigma_{\text {Bstch }}$ & $0.24_{\{0.14\}}$ & & & & & & & $\sigma_{E_{\text {rror }}}$ & $0.23_{(0.02)}$ \\
\hline
\end{tabular}

The standard error of each coefficient is presented in subscript in parentheses. All effects are significant (95\% confidence). Significance of fixed and random effects tested through 95\% confidence intervals generated by Markov Chain Monte Carlo methods. Variance components standard error is obtained by transformation from the standard error of the estimated parameter $(\ln \sigma 2)$.

The standard errors of the fixed effects are shown in Table 2. All terms of the model were significant. By considering the error structure arising from the experimental design (with batch-tobatch and inside-batch variability) the models developed would represent more accurately the "real" retail situation where a company would be expected to receive batches from different producers and with a significant variation between the batches of one producer. Where possible, this variability was separated into its different components (the batch-to-batch and insidebatch random effects) allowing for a more precise estimation of the model parameters and separating the uncertainty (resulting from the experimental measurement) from the variability (originating from the natural product diversity). This separation provided the basis for the analysis of variability in the quality attributes presented below.
In Fig. 2, contour plots of the storage conditions with zero time derivatives of the quality indicators for the three tissues at different temperature and relative humidity values are presented. This hypothesis of a zero slope would provide a weak hypothesis given the fact that even if there might not be any "real" zero slope (eventually the mushrooms quality will decrease) a zero slope simply would mean a non-observable change in the time range of the experiment given the experimental error. From the information contained in the present experiment that set of conditions would be the most favourable to preserve the quality attributes of the mushrooms unchanged.

Optimal storage guidelines for mushroom with temperatures between 1 and $3 \cdot \mathrm{C}$ (as low as possible in chilled storage) and as high a relative humidity as possible, have been reported (Tongkun, 2000). This policy was been found to be optimal to 
(a)

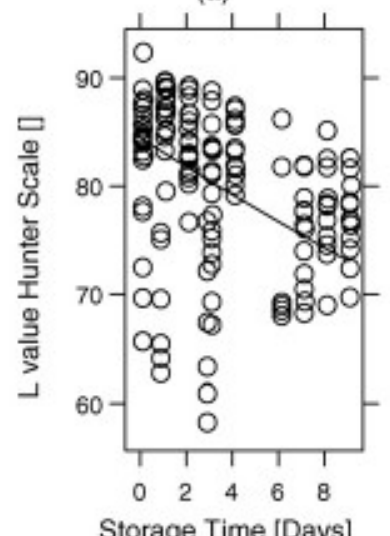

(d)

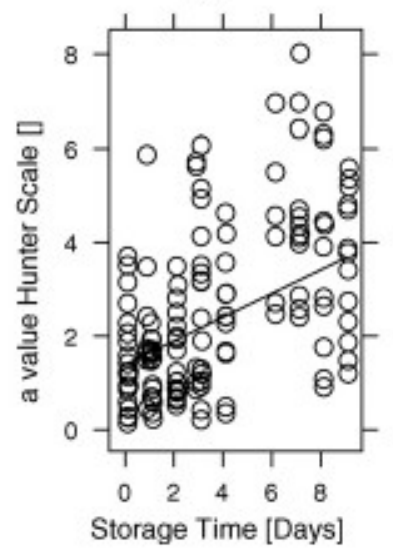

(b)

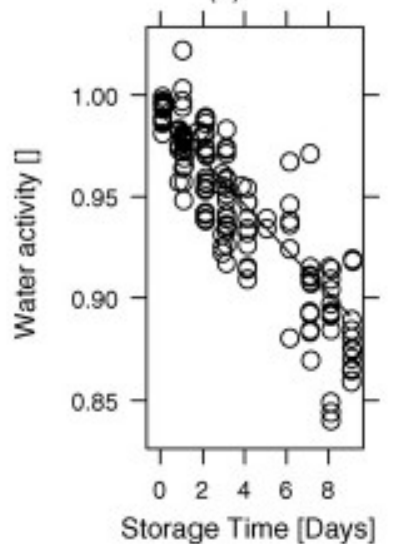

(e)

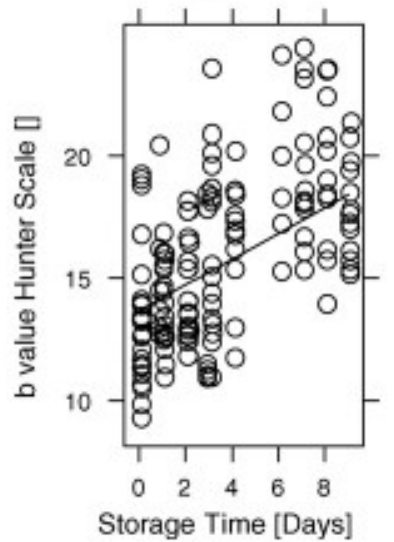

(c)

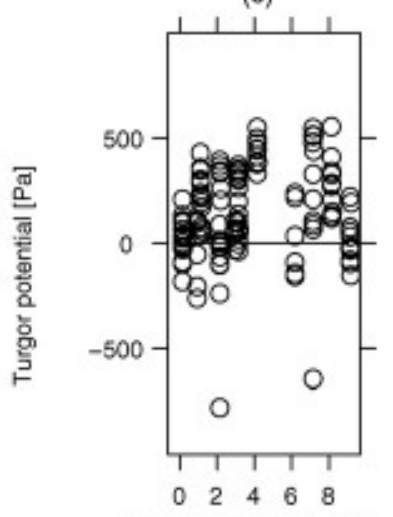

Storage Time [Days]

Fig. 1. Quality attributes kinetics of a batch of mushrooms stored at $5 \circ \mathrm{C}$ and $70 \%$ relative humidity. The continuous line represents the model prediction for the average population of the model. The different quality attributes in each of the subplots are: (a) L-value Hunter Scale, (b) water activity, (c) turgor potential, (d) a-value Hunter Scale, (e) b-value Hunter scale and (f) total mushroom weight.

preserve the weight of the mushrooms (see Table 2, no quadratic effects). However, this might not be the case for the preservation of other quality attributes.

In the case of the mushroom cap (see first inset in Fig. 1), higher storage temperatures (with less energy expenditure) of the order of 5-6.C and relative humidity close to saturation (in an impermeable package) might be sufficient to preserve optimally the colour of the mushrooms (in terms of their $L$ and a values). The turgor and texture of the mushrooms cap might as well be preserved using lower relative humidities of $80 \%$ (although drying of the tissue might become an undesirable trait).

When taking into account the quality attributes of the gills, Fig. 1 indicates: (i) similar conditions as to the cap for the preservation of the colour of the gills and (ii) that an optimal water activity avoiding the drying of the mushroom tissue through the gills could be achieved using high relative humidity (above $90 \%$ ) but without the need to spend energy in refrigeration at high temperature.

Finally, the stipe showed only one quality parameter with zero derivative in the domain under investigation (the water activity) and indicated that preservation of the water gradient would be achieved at high storage temperatures and relative humidities.
If a single optimal condition of storage was to be selected for all quality criteria Fig. 2 points to two possible options: (i) around $5 . \mathrm{C}$ and relative humidity around saturation, trying to maintain cap and gills colour, minimise weight losses or (ii) below $3 \circ \mathrm{C}$ and relative humidities around $95 \%$ to preserve the colour of cap and gills and the water activity in the gills, compensating for transpiration.

\subsection{Assessment of variability}

Postharvest product behaviour is inherently affected by omnipresent biological variation (Talasila and Cameron, 1995; Saltveit, 2003). Limiting biological variation as much as possible by sorting and grading the product at the different stages in postharvest chain was proven a successful technique to control postharvest shelf-life, however certain products present an inherent variability that makes them difficult to manage and postharvest technology has recently developed an interest in this area (Hertog et al., 2004, 2007a,b; Schouten et al., 2004).

The models presented in the literature in general have pooled all the variability of the mushrooms in a producer/distributor/retail situation, principally at the initial state 


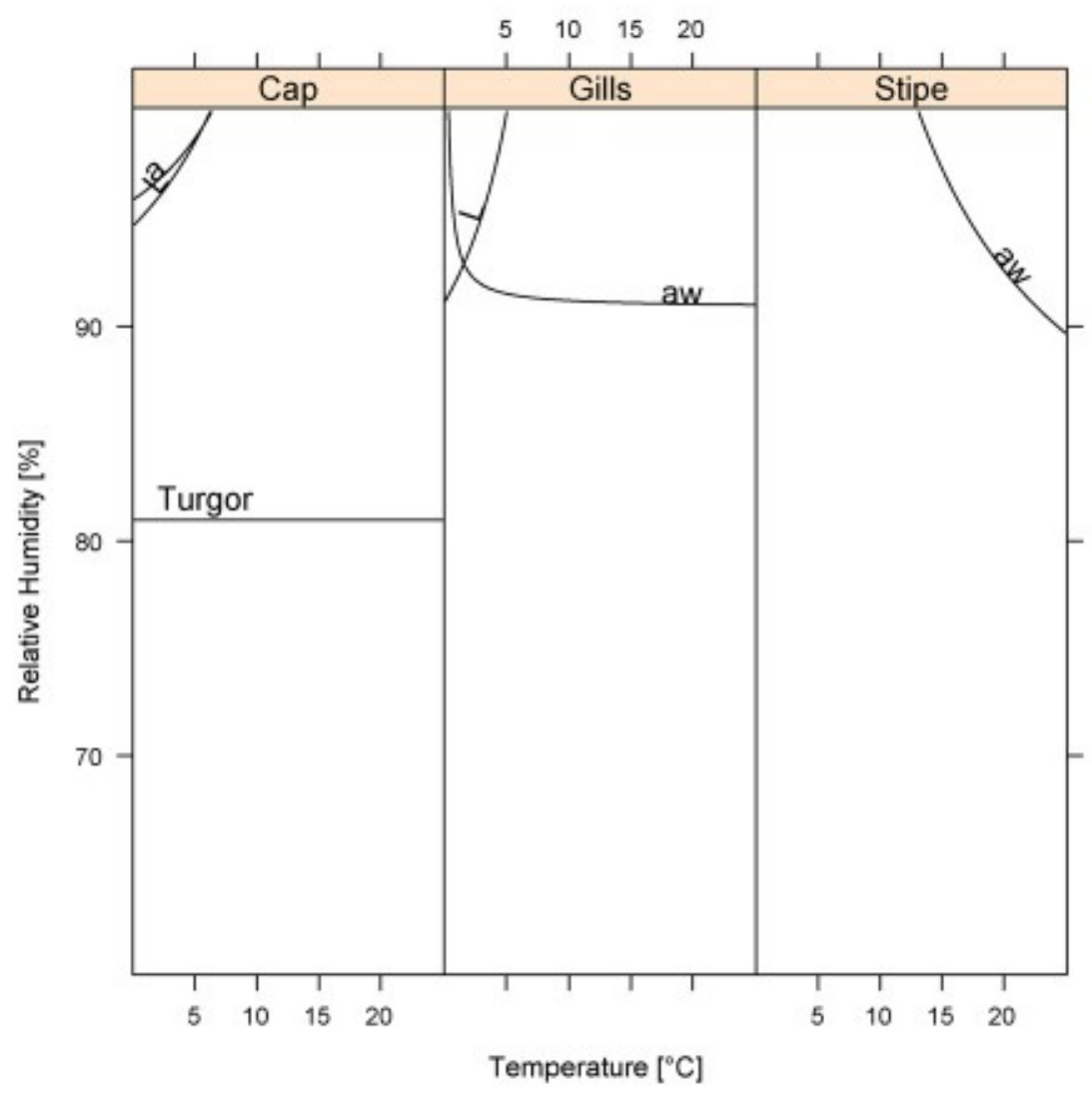

Fig. 2. Zero-derivative contour lines for the kinetics of quality decay of each tissue in respect of temperature and relative humidity.

(Hertog et al., 2007b). The effect of the low temperature and relative humidity of the refrigerated storage/distribution on the slope of the quality factor change was deemed strong enough not to be influenced by the random effects. This was tested by fitting models with random effects in both intercept and slope and comparing them (using a log-likelihood test on REML fitted models) against the intercept-only random effect models. All models with only initial state random effect for all responses, except for the weight loss, passed the test. This result was in accordance with the general assumption in postharvest technology that practices such as grading and sorting produce before storage would be essential in reducing the variability on how a product is affected by storage/processing.

The individual component percentage (ICP) of the different parts of the model were presented in Table 3. Approximately $60 \%$ of the variation of the data was explained by the fixed part of the model, considering an average of all the responses. The
Luminosity value, the $b$ value and the water activity were the responses which were better "controlled" by the temperature and relative humidity storage, with over $73 \%$ of the total variance of the data explained by the fixed effect of the model.

The a value and the turgor were the quality attributes that had a higher variability, and particularly in the case of the turgor this might be due to the high variability between mushrooms and the experimental error in the determination. Due to this high variability this property will not be considered for further discussion.

The batch-to-batch and the inside-batch variability represented approximately the $22 \%$ of the total variability of all the responses analyzed (which amounted to $35 \%$ of the total measurement), with responses that had a bigger variability than others (i.e., the a value and the weight).

The average variability between batches and the inside batches variability of all of the quality attributes was more or

Table 3

Individual component percentage (ICP) of variance components in fitted linear mixed effect models

\begin{tabular}{|c|c|c|c|c|}
\hline Quality parameter & Fixed effects $(\%)$ & Between batches (\%) & Inside batches $(\%)$ & Residual (\%) \\
\hline $\log (a w)$ & 82 & 4 & 11 & 1.4 \\
\hline Turgor & 0.6 & & 99.4 & $\sim 0$ \\
\hline $\log (\mathrm{L})$ & 78 & 10 & 9 & 1.4 \\
\hline a & 43 & 10 & & 42 \\
\hline $\mathrm{b}$ & 73 & 14 & & 4 \\
\hline $\log$ (weight) & 67 & $\begin{array}{l}11 \\
16\end{array}$ & 12 & 16 \\
\hline
\end{tabular}


less of the same magnitude. Considering all the responses, the sum of the random effect variances increased $11 \%$ when working with mushrooms coming from different producers, different seasons and different origins, in comparison with a variability of $11 \%$ that each of the produced batches presented (probably arising from a single production tunnel). If mushrooms shelf-life experiments were performed using only one producer (with the danger of an associated bias), the expected reduction of variability would not be very large (a reduction by half) and still researchers would have to face a large variability.

It can be seen in Table 3 that there were some properties ( $\mathrm{L}$ value, $\mathrm{b}$ value, $\mathrm{aw}$ and possibly the weight loss) which would be more controllable and where, if appropriate storage policies are devised, the appearance of out of specification batches will be low. However, the high variability in some properties, specially the turgor and to some degree the a value indicated that even devising optimal control policies to preserve those quality attributes of the product, the inherent variability between mushrooms might produce non-sensitive improvements.

Finally, considering both aspects of the feasibility of an optimal condition and the relative importance of the natural variability of the product in the quality attribute, if a refrigerated storage policy was devised in terms of preserving mushrooms, the preservation of the $L$ value, a value and the water activity should be the prime targets, with turgor the lowest priority in terms of control.

\section{Conclusions}

A study of the kinetics of the principal quality parameters of A. bisporus spp. tissues under different temperature and relative humidity conditions was performed. The kinetic behaviour was modelled taking into account the batch-to-batch and betweenbatches variability and optimal conditions of storage for the different quality parameters. Optimal storage conditions for mushrooms were found at low temperature $(\sim 5 \circ \mathrm{C})$ and high relative humidity $(\sim 100 \%)$ or low temperature $(\sim 3 \circ \mathrm{C})$ and lower relative humidity $(\sim 95 \%)$. Variability between-batches of mushrooms and between mushrooms in a batch were identified as relevant contributors to the total variability.

The importance of variability in a retail situation was assessed, with an average of $35 \%$ "uncontrollable variation" considering all the responses.

\section{Acknowledgment}

This material is based upon work supported by the Science Foundation Ireland under Grant No. 04/BR/E0073.
Beelman, R.B., Royse, D., Chikthmmah, N., 2003. Bioactive components in Agaricus bisporus (J.LGE) imbach of nutritional, medicinal or biological importance. Int. J. Med. Mushroom 5, 1-18.

Brennan, M., Le Port, G., Gormley, R., 1999. The effect of sodium metabisulphite on the whiteness and keeping quality of sliced mushrooms. Lebens. Wissen. Technol. Food Sci. Technol. 32, 460-463.

Brennan, M., Le Port, G., Gormley, R., 2000. Postharvest treatment with citric acid or hydrogen peroxide to extend the shelf life of fresh sliced mushrooms. Lebens. Wissen. Technol. Food Sci. Technol. 33, 285-289.

Burton, K.S., 1986. Quality-investigations into mushroom browning. Mushroom J. $158,68-70$.

Burton, K.S., 1989. The quality and storage life of Agaricus bisporus. Mushroom Sci. 12, 287-293.

Burton, K.S., Noble, R., 1993. The influence of flush number, bruising and storage temperature on mushrooms quality. Postharvest Biol. Technol. 3 , $39-47$.

Burton, K.S., Frost, C.E., Atkey, P.T., 1987. Effect of vacuum cooling on mushroom browning. Int. J. Food. Sci. Technol. 22, 599-606.

Carey, A.T., O'Connor, T.P., 1991. Influence of husbandry factors on the quality of fresh mushrooms (Agaricus bisporus). Mushroom Sci. 13, 673682.

Cliffe-Byrnes, V., O'Beirne, D., 2007. Effects of gas atmosphere and temperature on the respiration rates of whole and sliced mushrooms (Agaricus bisporus)_implications for film permeability in modified atmosphere packages. J. Food Sci. 72, 197-204.

Davidian, M., Giltinan, D. (Eds.), 1995. Nonlinear Models for Repeated Measurement Data. Chapman \& Hall, London.

Eamus, D., Jennings, D.H., 1984. Determination of water solute and turgor potential of mycelium of various basidiomycete fungi causing wood decay. J. Exp. Biol. 35, 1782-1786.

Escriche, I., Serra, J.A., Gomez, M., Galotto, M.J., 2001. Effect of ozone treatment and storage temperature on physiochemical properties of mushrooms (Agaricus bisporus). Food Sci. Technol. Int. 7, 251-258.

Fonseca, S.C., Oliveira, F.A.R., Frias, J.M., Brecht, J.K., 2002. Application of mathematical modelling and computer simulation to the design of modified atmosphere packages accounting for product variability. In: Balsa-Canto, E., Mora, J., Banga, J.R., Onate, E. (Eds.), Computational Techniques in Food Engineering. Intl. Ctr. Numerical Meth. Eng. (CIMNE), Barcelona, pp. $70-84$.

Frankhuizen, R., Boekestein, A., 1995. A non-destructive determination of moisture content of fresh mushrooms by near infrared (NIR) spectroscopy. In: Elliot, T.J. (Ed.), Mushroom Science XIV, Science and Cultivation of Edible Fungi 2. A.A. Balkema, Rotterdam, pp. 755-763.

Gabrielen, G., 2001. A multi-level model for preferences. Food Qual. Prefer. 12, 337-344.

Griffin, D.M., 1981. Water and microbial stress. Adv. Microb. Ecol. 5, 9196.

Gurka, M.J., 2006. Selecting the best linear mixed model under REML. Am. Stat. $60,19-26$

Hertog, M.L.A.T.M., Lammertyn, J., Desmet, M., Scherlinck, N., Nicolai, B.M., 2004. The impact of biological variation on postharvest behaviour of tomato fruit. Postharvest Biol. Technol. 34, 271-284

Hertog, M.L.A.T.M., Lammertyn, J., Scheerlinck, N., Nicola“, B.M., 2007a. The impact of biological variation on postharvest behaviour: the case of dynamic temperature conditions. Postharvest Biol. Technol. 43, 183-192.

Hertog, M.L.A.T.M., Lammertyn, J., Scheerlinck, N., Nicola”, B.M., 2007b.1 Managing quality variance in the postharvest food chain. Trends Food Sci. Technol. 18, 320-332.

Lammertyn, J., Ketelaere, B., de Marquenie, D., Molenberghs, G., Nicolai, B.M., 2003. Mixed models for multicategorical repeated response: modelling the time effect of physical treatments on strawberry sepal quality. Postharvest Biol. Technol. 30, 195-207.

Lammertyn, J., Desmet, M., Scheerlinck, N., Nicolai, B.M., Hertog, M.L.A.T.M., 2004. The impact of biological variation on postharvest behaviour of tomato fruit. Postharvest Biol. Technol. 34, 271-284.

Lukkasse, L.J.S., Polderdijk, J.J., 2003. Predictive modelling of postharvest quality evolution in perishables, applied to mushrooms. J. Food Eng. 59, $191-198$

\section{References}

AOAC, 1995. Official Methods of Analysis, 16th ed. Association of Official Analytical Chemists, Arlington.

Beecher, T.M., Magan, N., Burton, K.S., 2000. Water potentials and soluble carbohydrates concentrations in tissues of freshly harvested and stored mushrooms (Agaricus bisporus). Postharvest Biol. Technol. 22, 121-131. 
Mahajan, P.V., Oliveira, F.A.R., Macedo, I., 2007a. Effect of temperature and humidity on the transpiration rate of the whole mushrooms. J. Food Eng. 88, 281-288.

Mahajan, P.V., Oliveira, F.A.R., Montanez, J.C., Frias, J.M., 2007b. Development of user-friendly software for design of modified atmosphere packaging for fresh and fresh-cut produce. Innov. Food Sci. Emerg. Technol. 8, 84 92.

Money, N.P., 1994. Osmotic adjustments and the role of turgor in mycelial fungi. In: Wessels, J.G.H., Meinhardt, F. (Eds.), The Mycota - Growth, Differentiation and Sexuality. Springer-Verlag, Heidelberg, Germany, pp. 67-88.

Pai, T., 2000. Effects of storage environmental conditions on weight loss whiteness change and microbial activity of mushrooms (Agaricus bisporus). Agric. Chem. Biotechnol. 43, 161-164.

Pardo, A., De Juan, J.A., Pardo, J.E., 2001. Fisiolog'a post-cosecha, calidad yı conservaci' n del champi on cultivado Agaricus bisporus (Lange) imbach.on' Acta Aliment. 322, 107-117.

Pinheiro, J.C., Bates, D.M. (Eds.), 2000. Mixed-effects Models in S and SPLUS'. Springer-Verlag, New York, USA.

Roy, S., Anantheswaran, R.C., Beelman, R.B., 1995. Fresh mushrooms quality as affected by modified atmosphere packaging. J. Food Sci. 60 , 334-340.
Saltveit, M.E., 2003. Is it possible to find an optimal controlled atmosphere? Postharvest Biol. Technol. 27, 3-13.

Schouten, R.E., Jongbloed, G., Tijskens, L.M.M., Kooten, O.-V., 2004. Batch variability and cultivar keeping quality of cucumber. Postharvest Biol. Technol. 32, 299-310.

Shorten, P.R., Kubaczka, M., Soboleva, T.K., 2004. Partitioning of the variance in the growth parameters of Erwinia carotovora on vegetable products. Int. J. Food Microb. 93, 195-208.

Talasila, P.C., Cameron, A.C., 1995. Modelling frequency distribution of steadystate $\mathrm{O}_{2}$ partial pressures in modified-atmosphere packages. J. Food Proc. Eng. 18, 199-217.

Tijskens, L.M.M., Eccher Zerbini, P., Schouten, R.E., Vanoli, M., Jacob, S., Grassi, M., Cubeddud, R., Spinelli, L., Torricelli, A., 2007. Assessing harvest maturity in nectarines. Postharvest Biol. Technol. 45, 204-213.

Tongkun, P., 2000. Effects of storage environmental conditions on weight loss, whiteness change, and microbial activity of mushrooms (Agaricus bisporus). Agric. Chem. Biotechnol. 43, 161-164.

Varoquaux, P., Gouble, B., Barron, C., Yildiz, F., 1999. Respiratory parameters and sugar catabolism of mushroom (Agaricus bisporus Lange). Postharvest Biol. Technol. 16, 51-61.

Vizhanyo, T., Felfoldi, J., 2000. Enhancing colour differences in images of diseased mushrooms. Comp. Elec. Agric. 26, 187-198. 